\title{
SITUACIÓN DE LOS INCENDIOS FORESTALES DE VEGETACIÓN NATIVA EN LA REGIÓN DE VALPARAÍSO, CHILE CENTRAL*
}

\author{
Miguel Castillo Soto ${ }^{1}$, Francisco Rodríguez y Silva² y Juan Ramón Molina² \\ 1 Laboratorio de Incendios Forestales. Facultad de Ciencias Forestales y Conservación \\ de la Naturaleza. Universidad de Chile. Casilla 9206. Santiago de Chile. \\ migcasti@uchile.cl \\ 2 Departamento de Ingeniería Forestal. Universidad de Córdoba. Campus de \\ Rabanales. 14071, Córdoba. España. ir1rosif@uco.es \\ Departamento de Ingeniería Forestal. Universidad de Córdoba. Campus de Rabanales. \\ 14071, Córdoba. España. o92momaj@uco.es
}

\begin{abstract}
Resumen: Se estudia ocurrencia de incendios forestales en un paisaje vegetal costero de la Quinta Región de Chile, para el período 1986-2010. Para este propósito se seleccionó un área con presencia de especies de alto valor científico, entre ellas el bosque de Jubaea chilensis (Palma chilena), altamente fragmentado por la acción por la acción del fuego y la expansión urbana. Por medio de análisis de NDVI y componentes principales basados en información de satélite y bases de datos geográficas de incendios, fue posible identificar y calificar áreas de alta sensibilidad, en donde coexiste el conflicto de expansión de las ciudades y el retroceso sostenido del antiguo bosque nativo, en los últimos 25 años.
\end{abstract}

Palabras clave: Incendio Forestal, Paisaje, Teledetección, Valparaíso (Chile).

\begin{abstract}
Occurrence and severity are studied of forest fires in a vegetable coastal landscape of the Fifth Region of Chile, for the period 1986-2010. For this purpose an area was selected by presence of species of high scientific value, between them the forest of Jubaea chilensis (Chilean Palm), highly fragmented by the action of the fire and the urban expansion. By means of NDVI's analysis and principal components based on information of satellite and geographical databases of fires, it was possible to identify and to qualify areas of high sensibility, where there coexists the conflict of expansion of the cities and at the same time the continuous backward of the former native forest, in the last 25 years.
\end{abstract}

Keywords: Forest Fire, Landscape, Remote Sensing, Valparaíso (Chile)

${ }^{1}$ Recibido: 23-03-10. Aceptado: 07-06-10. 


\section{Introducción}

La creciente demanda de bienes y servicios existentes en territorios planificados para ocupación urbana, y el retroceso sostenido de masas forestales nativas, son dos procesos que coexisten en muchas regiones mediterráneas, y en donde el problema de los incendios forestales actúa como agente modificador de sus paisajes, y como una consecuencia evidente de la actividad humana en áreas donde el riesgo de este tipo de fenómenos reviste niveles de alta gravedad.

Las estadísticas de incendios en Chile, indican que en promedio ocurren aproximadamente 6.200 incendios de vegetación, desglosados principalmente entre plantaciones forestales y arbolado nativo. En términos espaciales las cifras de ocurrencia se concentran fuertemente en la región central, particularmente en el área costera de Valparaíso y Viña del Mar. El siguiente gráfico ilustra la relación de la superficie quemada, respecto a la cantidad de incendios, para un período de 10 años.

Las cifras indican que los incendios de vegetación corresponden principalmente a pequeñas superficies. Sin embargo, más del $90 \%$ de los daños directos e indirectos se concentran en una cantidad reducida de incendios, pero con superficies superiores a

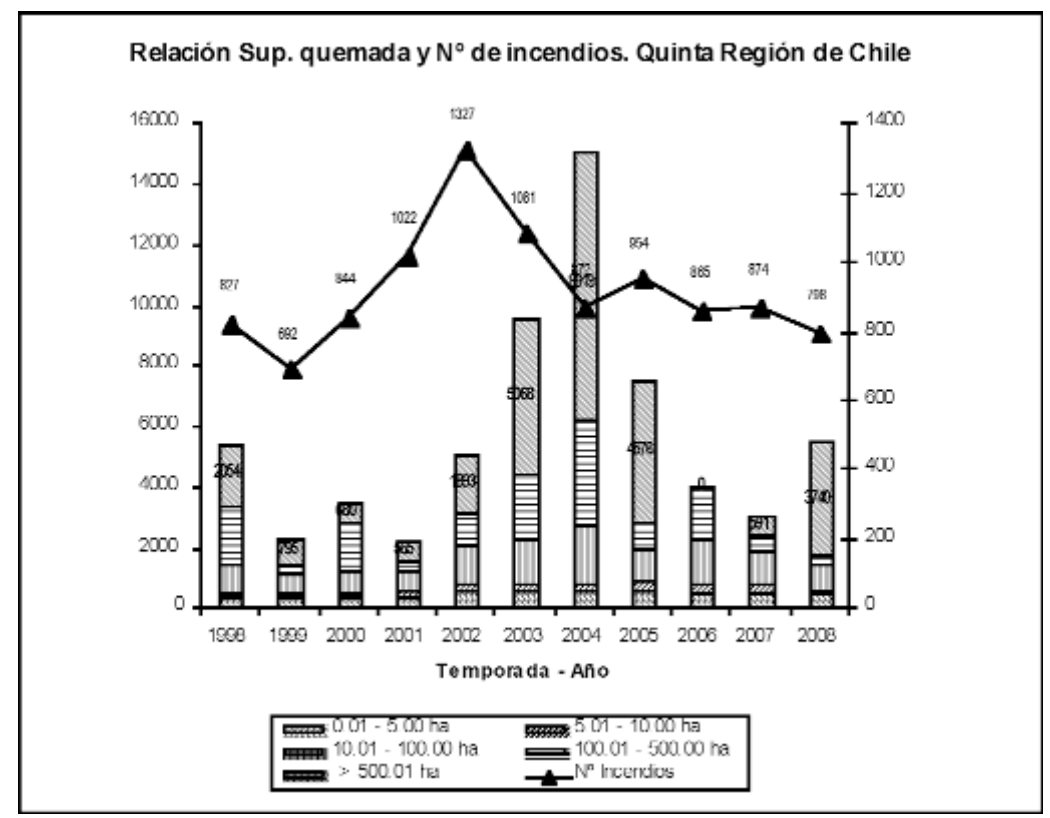

Gráfico 1. Composición de incendios forestales, clasificados por clases de tamaño. Elaboración: Laboratorio de Incendios Forestales. Universidad de Chile. 
las 100 hectáreas. Estas cifras se consideran altas, en relación al territorio en que se producen, a diferencia de otros países con ecosistemas similares en donde es común encontrar incendios de tamaño superior a las 1.000 o más hectáreas de vegetación nativa.

Respecto a las causas por las cuales se producen los incendios forestales, prácticamente el 100\% de la ocurrencia se debe a la actividad irresponsable del hombre, reflejada en errores en el tratamiento de la vegetación combustible, en quemas ilegales, y en una alta proporción a intencionalidad, esta última concentrada en centros de recreación, y en cercanías de caminos.

Este artículo, aborda la situación de los incendios considerando datos estadísticos e imágenes de satélite del año 1986, con una extensión del estudio hasta el año 2010, en áreas y sectores pertenecientes a la Zona Mediterránea Costera de la Quinta Región de Chile. La relevancia de la investigación radica también en el estudio de sectores geobotánicamente valiosos de palma chilena (Jubaea chilensis Mol. Baillon), una de las especies más preciadas de la flora nativa chilena que hace siglos formaba parte del antiguo bosque esclerófilo de estas latitudes, y que hoy se encuentra en un evidente estado de degradación.

\section{2. Área de estudio}

El área de estudio corresponde a un territorio comprendido entre las coordenadas geográficas Lat 32(S) 42' - Long: 71(W) 30'; Lat 33(S) 48' - Lon: 71(W) 0' (figura 1). La topografía costera es de lomajes suaves, cuyas alturas máximas no superan los 770 m.s.n.m., con laderas cóncavas a convexas. 4 a $5 \mathrm{~km}$ hacia el interior, se distinguen sectores de planicies interrumpidos por quebradas con altas pendientes, especialmente en cursos de agua principales.

El clima costero se caracteriza por la presencia de neblinas que se desplazan hacia los cerros interiores, conformando un topoclima típicamente templado, con temperaturas que oscilan entre $17^{\circ}$ y $25^{\circ}$ y, precipitaciones anuales del orden de $370 \mathrm{~mm}$ (Dirección Meteorológica de Chile, 2005).

La vegetación dominante, de acuerdo a Villaseñor (1977), se agrupa en seis categorías, y que actualmente corresponden a comunidades testigos de la cubierta vegetal primitiva que cubrió a la zona siglos atrás. Producto de la acción del hombre mediante la extracción de leña, frutos, ganadería y agricultura, entre las principales actividades, las categorías antes señaladas corresponden a Bosque Esclerófilo (árboles 


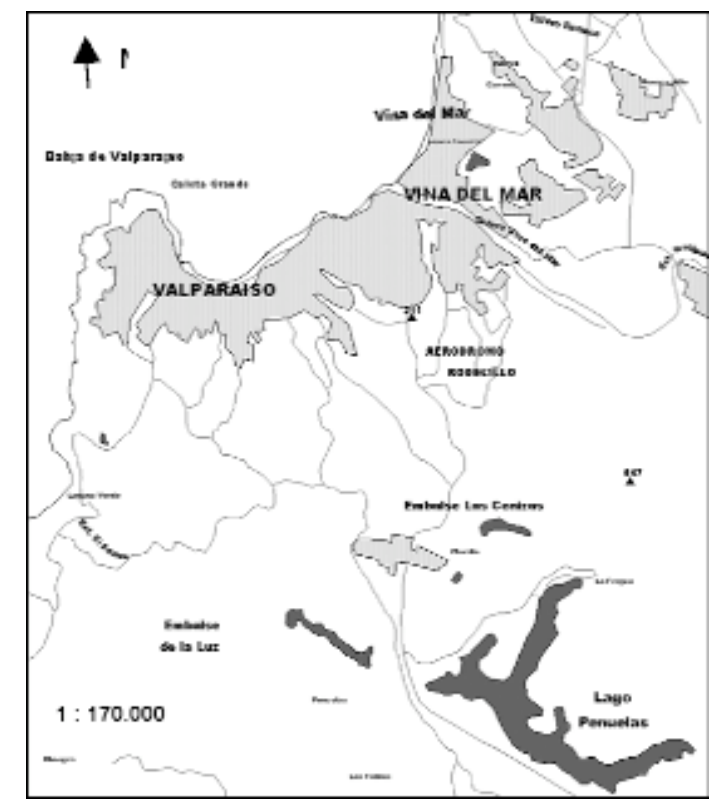

Figura 1. Área de estudio en el colinaje costero de la Quinta Región. Fuente: el autor.

que crecen sobre los 200 m.s.n.m en laderas preferentemente oeste), Bosque Higrófito (árboles que crecen en laderas de umbría y fondos de quebradas), Matorral Esclerófilo (formación arbustiva que presenta coberturas variables), Matorral Higrófito (árboles y matorral degradado situado en sectores húmedos, preferentemente a orilla de canales y esteros), Matorral Xerófilo (matorral secundario, dispuesto en laderas de exposición norte), Palmares (comunidades dispuestas en laderas bajas y de preferencia en exposiciones oeste, frente al mar), Puyales (agrupaciones de plantas que crecen en todas las condiciones de laderas y altitudes en el cordón costero).

\section{Materiales y métodos}

Fuller (2001), Gergel y Turner (2002) y Castillo (2006), recomiendan abordar este tipo de estudios considerando más de una escala de análisis. Se recopilaron cartas topográficas del área de interés a escalas 1:25.000 y 1:50.000, junto a información de red caminera, centros poblados, hidrografía y topónimos. Respecto a antecedentes meteorológicos, se utilizaron bases de datos de temperaturas y lluvias, proporciona- 
das por la Dirección Meteorológica de Chile para el período comprendido entre 19862007. Adicionalmente se utilizaron las estadísticas oficiales de ocurrencia de incendios forestales elaboradas por la Corporación Nacional Forestal (CONAF, 2005), y reportes cartográficos de siniestros ocurridos durante los veranos de 2004 a 2009. Estos últimos antecedentes fueron adaptados a los objetivos de este trabajo mediante la utilización de un SIG.

Se utilizaron imágenes satelitales del sensor Landsat TM, abarcando el lapso comprendido entre 1986 y 2010. Para su utilización, se efectuó una preselección de las imágenes y recorte espacial del área de interés, considerando la estación del año y la nubosidad contenida en ellas. En tal sentido se eligieron aquellas escenas comprendidas entre los meses de Diciembre a Marzo, por presentar similar comportamiento espectral en las distintas bandas de cada imagen. Se efectuaron las correcciones geométricas, atmosféricas y radiométricas para su utilización. En cada una de ellas, se realizó una composición en falso color estándar, con el propósito de distinguir a primera vista, grupos espectrales asociados al uso del suelo, con énfasis en la identificación de sectores urbanos (tonalidades celestes a claras), y coberturas vegetales (colores más intensos asociados al rojo). Las imágenes fueron ecualizadas para lograr una mejora en el contraste. Adicionalmente se utilizó una fotografía aérea digital, tomada en el mes de febrero de 2001, la cual fue corregida y adaptada para su utilización en este estudio.

\section{Resultados}

A base de la utilización de registros cartográficos de incendios y siguiendo la metodología de Calle y Casanova (2002), y las técnicas expuestas en Burgan (1995), se analizaron los patrones espectrales de la imagen para la identificación de áreas quemadas, junto con determinar los principales incendios ocurridos en el período de análisis, y para las imágenes satelitales utilizadas. La imagen Landsat precedente, señala dos grandes incendios (marcados con líneas blancas) ocurridos en quebradas ubicadas en las cercanías del acceso principal a Valparaíso, y hacia el norte de la localidad de Placilla (figura 2).

Entre ambos siniestros, se consumieron más de 450 hectáreas entre matorrales y pastizales, constituyendo los principales eventos de esa temporada. Un seguimiento de aquellas áreas afectadas por el fuego para el año 1989 (imagen siguiente), indica una recurrencia en los patrones de localización de focos (lugares de inicio de los fuegos), aunque no existe una correlación entre los tamaños de las superficies afectadas. Las tonalidades en rojo señalan cubiertas vegetales de distintas clases, mientras que los tonos más claros y pardos (confinados a las quebradas), señalan ocupación de 


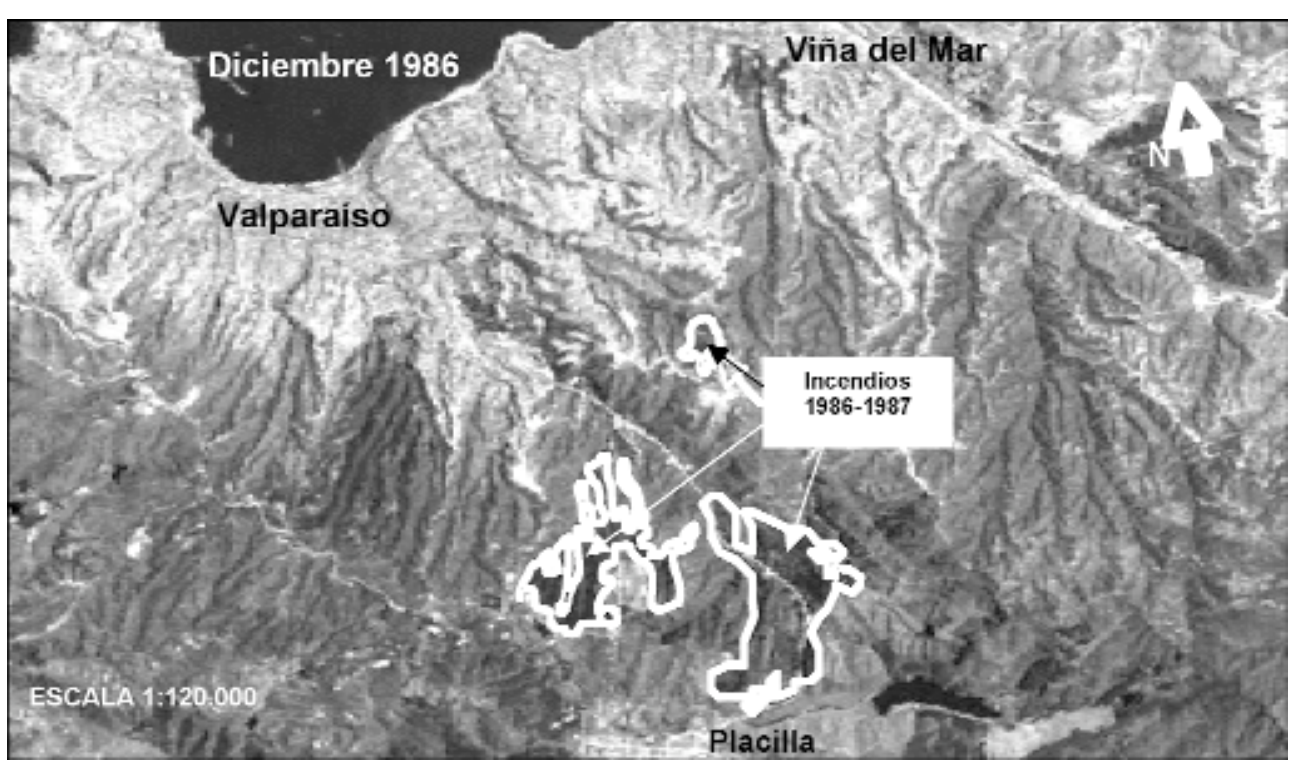

Figura 2. Imagen satelital en falso color estándar, tomada por el sensor Landsat en el mes de diciembre de 1986. En ella es posible distinguir áreas asociadas a centros poblados, vegetación y sectores quemados. Fuente: el autor.

suelo urbano. Cabe señalar que al final de la temporada de incendios 1986-1987 en la Quinta Región, se quemaron 14.872 hectáreas de vegetación natural, siendo una de las cifras históricas más altas, junto a las temporadas 1984-1985 y 1989-1990. Posteriormente se considera una imagen satelital captada en el mes de marzo de 1989, en donde se aprecia a primera vista, parte de la expresión de los daños descritos en el párrafo anterior. Extensas áreas quemadas son posibles de apreciar en prácticamente todos los sectores periféricos al límite sur y este de Valparaíso y Viña del Mar. En tal sentido, y tal como se señala en estudios realizados en la Región (Quintanilla y Castro, 1998; Quintanilla 1999 y 2000), la capacidad de recuperación de la vegetación natural se acota al rápido recubrimiento de espacios quemados con especies invasoras asilvestradas, dando paso a un paisaje modificado en donde la palma chilena experimenta un rápido retroceso en su población de distribución natural.

La imagen satelital en falso color estándar (figura 3), tomada por el sensor Landsat en el mes de marzo de 1989 señala las ubicaciones donde hubo incendios. Durante ese período estival, se quemaron 25.452 hectáreas de vegetación nativa, sólo en la Quinta Región. Se aprecia en la imagen que los principales siniestros se localizan en las inmediaciones de centros poblados y vías de comunicación. Hacia el norte de la 


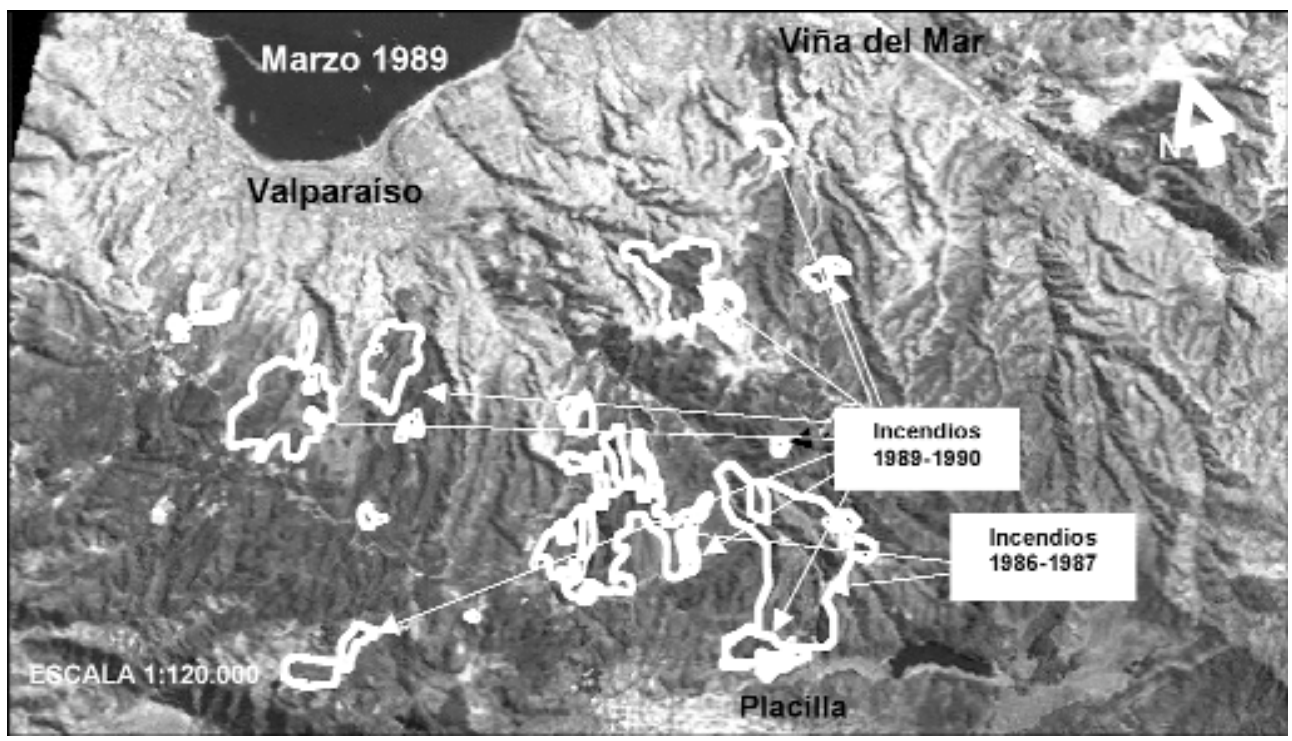

Figura 3. Situación de fuegos, durante el mes de marzo de 1989. Se indica además los fuegos ocurridos en la temporada 1986-1987. En líneas amarillas se indican las superficies dañadas en la temporada 1986-1987. Fuente: el autor.

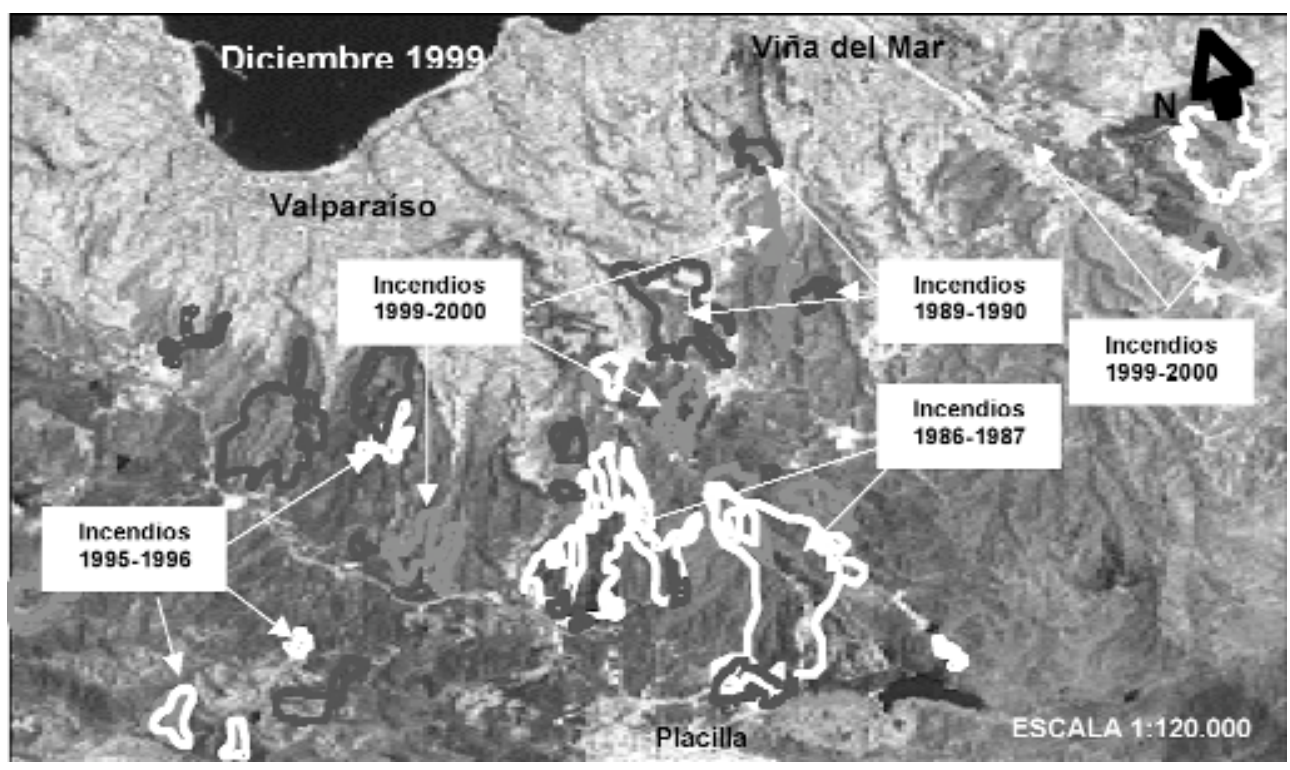

Figura 4. Situación de incendios en el área de interés, al mes de diciembre de 1999. La ocurrencia de incendios permanece asociada a la cercanía de vías de comunicación (ruta de acceso a Valparaíso), y quebradas del sector sur de Viña del Mar. Fuente: el autor. 
localidad de Placilla, se aprecia nuevamente la presencia de incendios, respecto a la imagen anterior.

Las estadísticas oficiales proporcionadas por la CONAF, indican una estabilidad en la cantidad de hectáreas quemadas de vegetación nativa para la Región, entre los años 1995 a 2001, alcanzando un promedio de 2.500 ha/año, por debajo de las 6.900 ha/año en un período de 34 años (1972-2005). Al mes de diciembre de 1999 (figura 4), se advierten nuevamente localizaciones en donde antes hubo episodios de fuego, especialmente en los sectores norte de la localidad de Placilla, y hacia el interior de las quebradas del sector sur de Viña del Mar. En cerros aledaños a poblados de Valparaíso y Viña, se concentra el mayor número de incendios, aunque de superficies menores a una hectárea.

\section{Discusión}

Como comentarios de la información contenida en las imágenes anteriormente expuestas, y considerando la localización y tamaño de los siniestros, existe una clara distribución espacial de eventos de fuego, confinados a sectores de quebradas y poblados periféricos a las ciudades de Valparaíso y Viña del Mar, como también a orilla de caminos principales y en el sector de Placilla y Embalse Las Cenizas, más hacia el interior del colinaje costero. Efectuado el seguimiento de ocurrencia, localización de incendios en el área de estudio, se verifica que en las áreas de interfaz urbanoforestal, la situación, lejos de disminuir, se ha ido agravando conforme el aumento de densidad de viviendas se concentra en la periferia de quebradas y cerros con alta carga de combustible vegetal disponible para su ignición y propagación violenta. Una revisión de ello, corresponde a un gran incendio de vegetación nativa ocurrido durante el verano de 2008, en el cual fueron afectadas 114 viviendas con consecuencia de vidas humadas y enormes pérdidas por daños directos a la infraestructura y medio ambiente. Un seguimiento satelital (figuras 5 y 6 ), demuestra que el problema sigue concentrándose en áreas de interfaz.

Por todo lo anterior, se identifican dos procesos que interactúan entre sí: por un lado la dinámica de ocupación del territorio en los últimos 25 años, en el cual los grandes ejes no han crecido sustantivamente pero sí han aumentado en densidad de ocupación, lo cual queda corroborado por estudios realizados en la misma región (SEVEIF, 2010). Como segundo aspecto, señalar que el nivel de gravedad de los incendios actuales (traducidos en la evaluación de su tamaño y forma o perímetro quemado) superan muchas veces la capacidad de reacción con que los recursos en combate pueden hacer frente, especialmente en períodos de simultaneidad de incendios. 


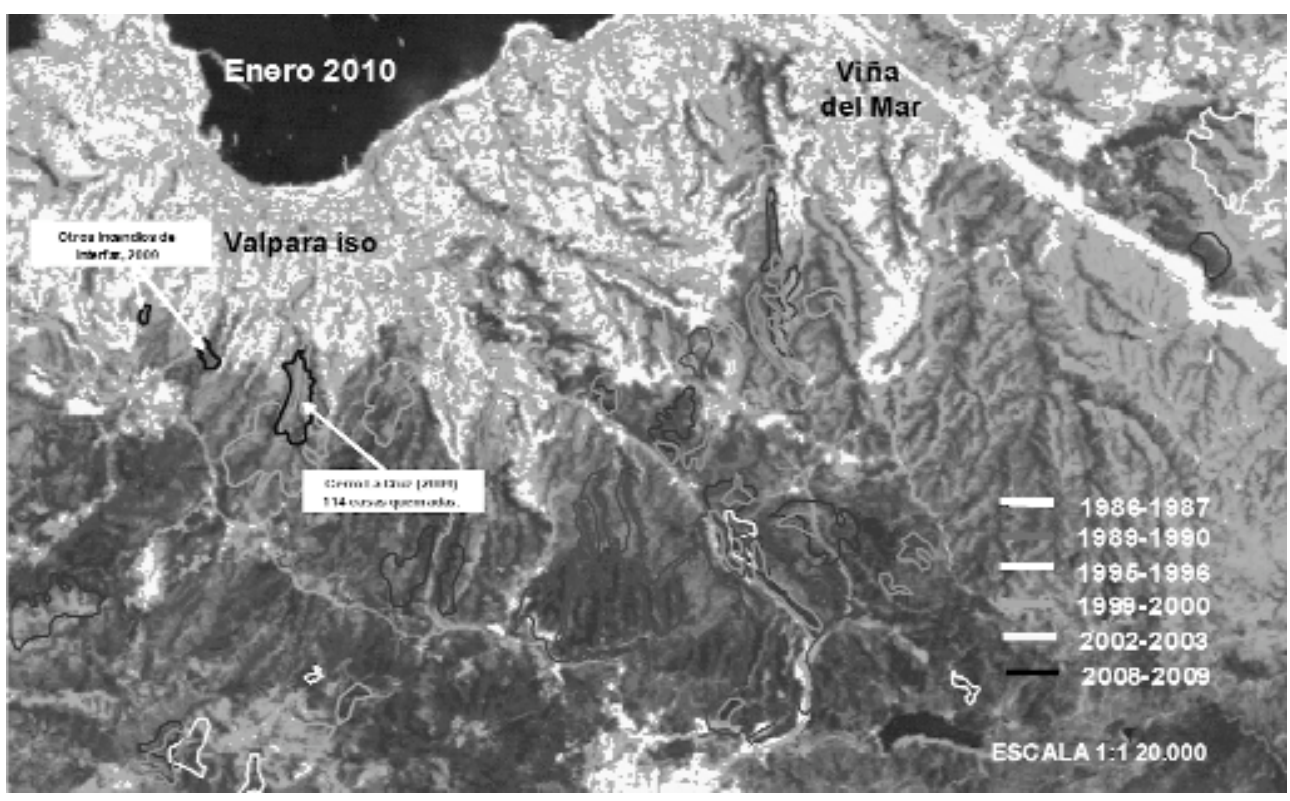

Figura 5. Situación de grandes incendios en áreas de interfaz al año 2010. Se verifica la recurrencia de áreas quemadas, con su consecuente deterioro en el paisaje vegetal. Fuente: el autor.

Se identifican patrones de recurrencia muy marcados, en donde es posible reconocer sectores afectados durante prácticamente todos los años, y que son posibles de apreciar en el tamaño, forma y distribución de las áreas quemadas.

El análisis satelital recién expuesto, se complementa con la caracterización de la ocurrencia de incendios forestales, para lo cual, se consideraron antecedentes históricos registrados por el sistema estadístico de la Corporación Nacional Forestal (CONAF), institución que posee datos confiables desde el año 1986. Esta información se encuentra codificada en coordenadas GEO-REF, lo cual significa que cada incendio se registra en una unidad homogénea (celda) de 400 hectáreas, organizada a su vez en celdillas de 100 hectáreas cada una. Para el almacenamiento espacial de los incendios, se empleó un software especialmente diseñado por el Laboratorio de Incendios Forestales de la Universidad de Chile, el cual transforma las coordenadas GEO-REF a coordenadas UTM, siendo posible asignar los parámetros necesarios para el calce espacial con los otros niveles de información. De esta manera, se registraron todos los incendios ocurridos entre las temporadas 1986-1987 a 2003-2010 (figura 7). 


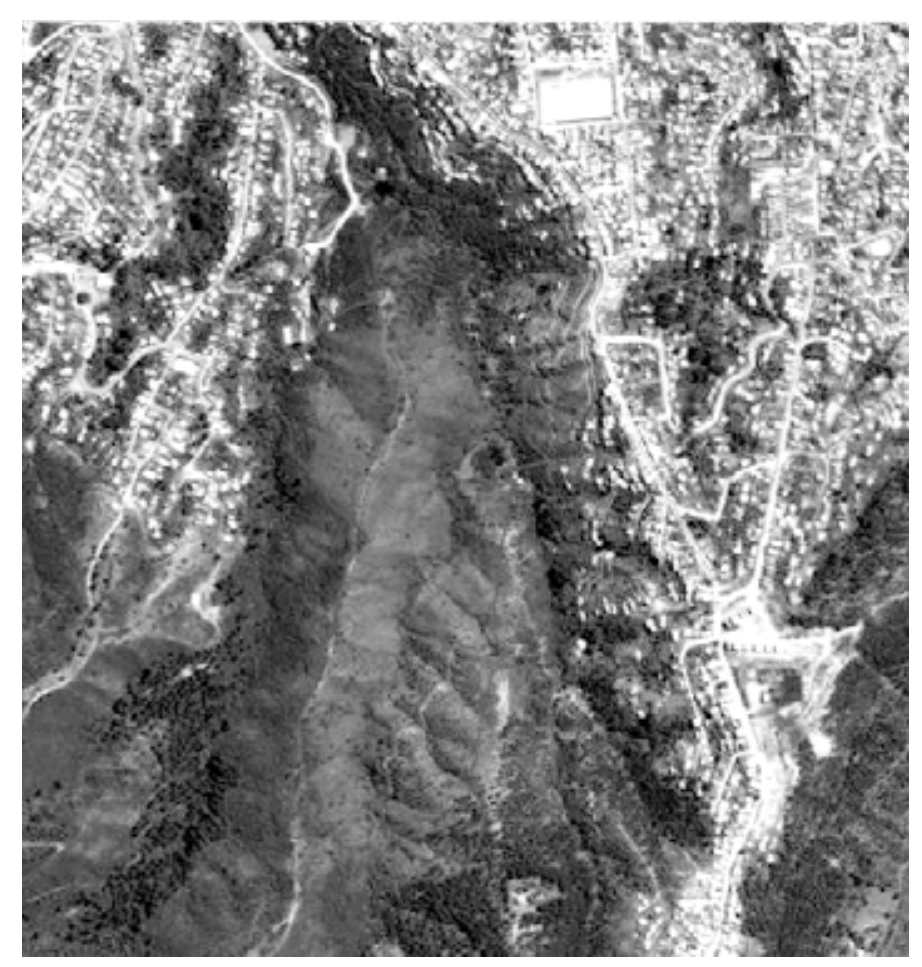

Figura 6. Imagen aérea que muestra en detalle el área quemada (el línea roja) por el incendio del año 2009, en un área densamente poblada de la Provincia de Valparaíso, Chile Central. Fuente: Corporación Nacional Forestal V Región de Chile, con modificaciones.

La base de datos de registros procesada y filtrada por categorías de tamaño, señala que los principales siniestros tienden a ubicarse multitemporalmente en las mismas localizaciones, es decir, a orilla de caminos, próximos a centros poblados y quebradas del sector sur de Valparaíso y Viña del Mar, en donde es posible apreciar valores importantes de frecuencia de incendios para los últimos 25 años.

Se aprecian importantes superficies quemadas en la temporada de incendios 1986/1987 en áreas de alto riesgo de incendios. De acuerdo a los datos estadísticos, sus localizaciones o lugares de inicio de ambos siniestros, se ubicaban en sectores de alta pendiente y muy próximo a la ruta principal que conecta Santiago con Valparaíso.

La temporada 1988-1989 se registra como una de las más severas en términos de los daños ocasionados por el fuego a la vegetación nativa. En el área de estudio, se identifican dos grandes incendios localizados en quebradas del sector sur de 


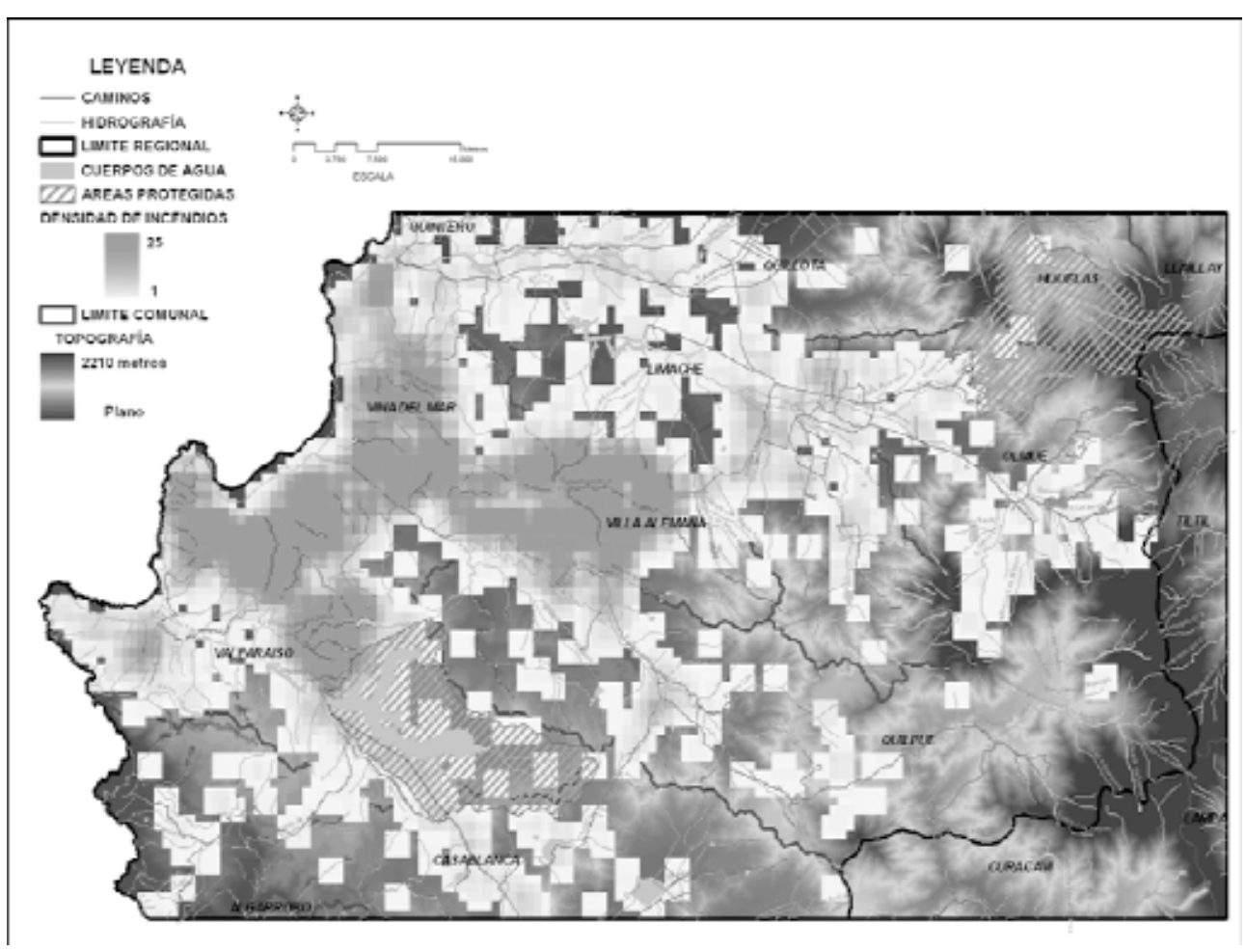

Figura 7. Mapa de densidad de incendios para el área en estudio. Sector litoral de Valparaíso y Viña del Mar. Las áreas marcadas en rojo corresponden a localizaciones que presentan las más altas tasas de ocurrencia, para un período de 25 años. La distribución de los ejes de expansión coinciden con estas áreas, como asimismo con las vías de comunicaciones. Fuente: el autor.

Valparaíso (quebradas El Pajonal y El Vergel) y otro en cerros aledaños a Viña del Mar Alto. La presencia de formaciones leñosas densas en las quebradas antes señaladas, sumado a las altas pendientes contribuye a que estos sectores sean recurrentemente afectados por el fuego, y por lo tanto, calificados como de alto riesgo de incendios.

Los antecedentes de frecuencia de incendios indican que los sectores aledaños a las quebradas de El Salto y Jardín Botánico se han quemado 10 veces en los últimos 15 años. La calificación de alto riesgo junto a la alta frecuencia de incendios, impide la recuperación de la vegetación, quedando detenida a estados de matorral degradado y leñosas altas abiertas.

La imagen satelital de diciembre de 1999 señala incendios superiores a 30 hectáreas localizados al norte del fundo Las Cenizas, a la salida Norte de Placilla y en sec- 
tor de El Manzano a orilla del acceso sur a Valparaíso. Estos sectores han sido calificados en categorías de riesgo moderado y elevado, de acuerdo a la clasificación de Quintanilla (1998).

La imagen de enero de 2010 señala un incendio de 36 hectáreas localizado al norte de Rodelillo, y muy cercano a sectores poblados. Se trata de lomajes suaves a moderados que han sido afectados por más de 12 incendios en los últimos 15 años, en áreas calificadas como de riesgo muy elevado. Conforme a los antecedentes estadísticos sobre ocurrencia y distribución espacial de los incendios acaecidos en el área de estudio y para los períodos analizados, se obtuvieron patrones de recurrencia, es decir, áreas que frecuentemente son afectadas por siniestros, y que cartografiados sobre el mapa de formaciones vegetales (Quintanilla, 1998), y las series de imágenes, dan como resultado la identificación de zonas críticas de ocurrencia (Figura 8). Las estadísticas de incendios permitieron determinar la frecuencia en que una unidad territorial (celda), ha sido recurrentemente quemada.

Si se comparan las imágenes satelitales de los años 1986 y 2010, es posible identificar patrones espaciales de recurrencia de incendios, y en consecuencia, tipologías de vegetación y paisajes afectados. Las leñosas altas abiertas, herbáceas, y leñosas altas y bajas, corresponden a los tipos de formaciones vegetales mayormente afectadas por el fuego.

Es posible además identificar un patrón de movilidad de la ocurrencia. Al contrastar los años de imágenes, se aprecia cómo los incendios han ido aumentando hacia el interior del sector sur de Viña del Mar y Valparaíso, especialmente en cerros localizados en áreas periféricas.

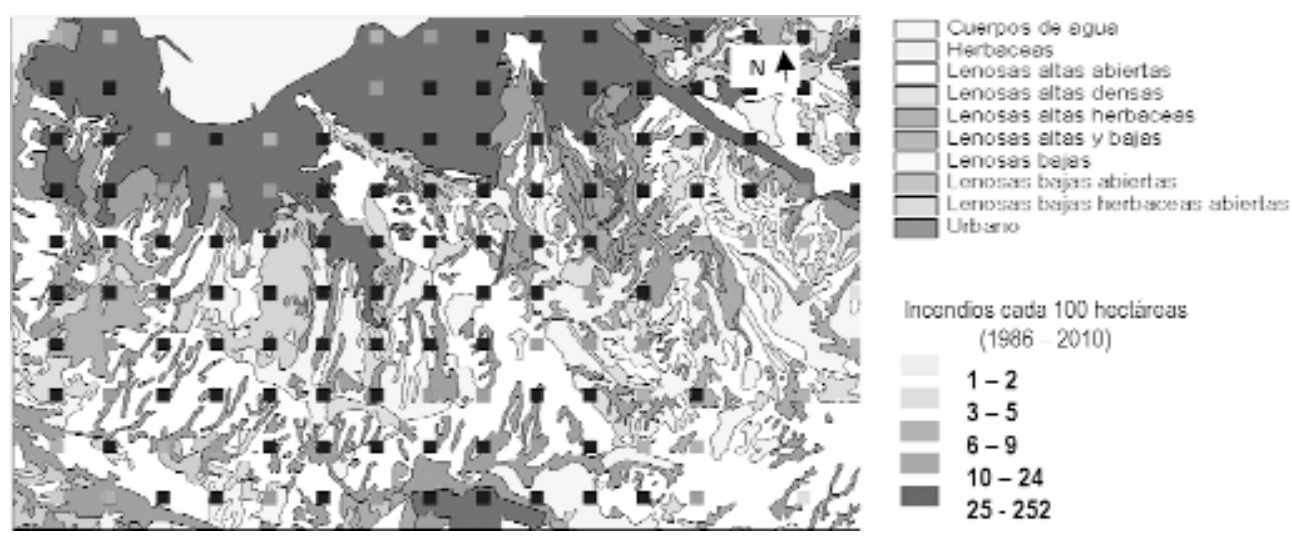

Figura 8. Cartografía de Combustibles (Quintanilla, 1998), e información cartografiada de incendios. Estos antecedentes permitieron apoyar el reconocimiento de las formaciones vegetales a partir de la clasificación supervisada para la serie de imágenes satelitales. 
Analizando la distribución espacial de áreas dañadas por el fuego, entre temporadas de incendios, se advierte una concentración creciente de eventos hacia los sectores sur-este de Valparaíso, Sur de Viña del Mar, en inmediaciones del Estero de Viña del Mar, en la periferia del aeródromo de Rodelillo y en el acceso norte a la localidad de Placilla. Estas áreas de ocurrencia han aumentado su intensidad, identificándose en promedio un aumento en 18 años en 3 a 5 eventos por localización. Sin embargo, no existen patrones claramente identificables respecto a los daños ocasionados por el fuego, como para la extensión de las áreas quemadas. Estos últimos aspectos muestran un comportamiento estadístico muy irregular.

Resulta particularmente visible el efecto en la concentración de incendios en partes bajas de laderas y basurales colindantes a instalación de casas en sectores de alta pendiente, no autorizadas para su construcción.

Respecto a las áreas de vegetación nativa mayormente afectadas por el fuego, existe una recurrencia de eventos concentrada en las secciones sur y oeste de la Hacienda Siete Hermanas, en quebradas de El Salto, Jardín Botánico, y cerros aledaños a los accesos a Viña del Mar y Valparaíso.

El efecto borde en las áreas más sensibles a la iniciación de fuegos es particularmente visible en la Ruta Las Palmas, en donde centenas de ejemplares adultos quedaron dispuestos a orilla de taludes y alta accesibilidad humana, producto del corte en la continuidad del paisaje. El efecto abrigo que tenían las poblaciones de palma se ha visto seriamente amenazado por la recurrencia de fuegos en estos sectores, en donde ya es posible ver la muerte de centenares de ejemplares adultos producto del tumbado y daños ocasionados por el fuego.

En un análisis a carta semidetallada (1:50.000), el valor NDVI obtenido de las imágenes de satélite identifica áreas recientemente quemadas caracterizadas por un valor cercano a cero, con fragmentos de vegetación invasora y escasa actividad fotosintética. En estos cerros es evidente la fragmentación del paisaje vegetal pues es posible apreciar una baja conectividad entre los parches de vegetación calificados como leñosas altas y bajas. La vegetación dominante corresponde a matorral nativo entremezclado con especies invasoras.

Los valores NDVI obtenidos a partir de las imágenes satelitales consideradas para este estudio, fueron clasificados en intervalos iguales, para efectos de facilitar la interpretación de los resultados respecto de la actividad fotosintética (tabla 1). 
Tabla 1. Clasificación de ND a partir de los resultados del NDVI.

\begin{tabular}{|c|l|}
\hline Rango NDVI & Estado de la vegetación (actividad fotosintética) \\
\hline $0-0,25$ & Bajo \\
$0,251-0,5$ & Medio \\
$0,51-0,75$ & Bueno \\
$0,751-1$ & Muy Bueno \\
\hline
\end{tabular}

Sobre la base de estos rangos, se identificaron los valores para los 12 incendios mayores a 20 hectáreas de vegetación nativa quemada, de un total de 47 eventos identificados en las imágenes. De esta manera, y de acuerdo a lo propuesto por Chuvieco (2000), fue posible establecer un seguimiento multitemporal del NDVI, permitiendo además relacionar sus resultados, con los antecedentes de la cartografía de riesgo de incendios elaborada por Quintanilla en 1998 (figura 9).

La base de datos de registros procesada y filtrada por categorías de tamaño, señala que los principales siniestros tienden a ubicarse multitemporalmente en las mismas localizaciones, es decir, a orilla de caminos, próximos a centros poblados y quebradas del sector sur de Valparaíso y Viña del Mar, en donde es posible apreciar valores importantes de frecuencia de incendios para los últimos 25 años.

Los resultados de la tabla 2, indican un comportamiento estacional muy acentuado a valores bajos de NDVI en áreas recientemente afectadas por el fuego, y a una paulatina recuperación del índice en años posteriores. Sin embargo, en esta aseveración debe considerarse la ocurrencia de incendios en años intermedios y para las mismas localizaciones quemadas, y la diferencia en el vigor de la vegetación respecto a su contenido de humedad en meses de invierno y comienzos de primavera.

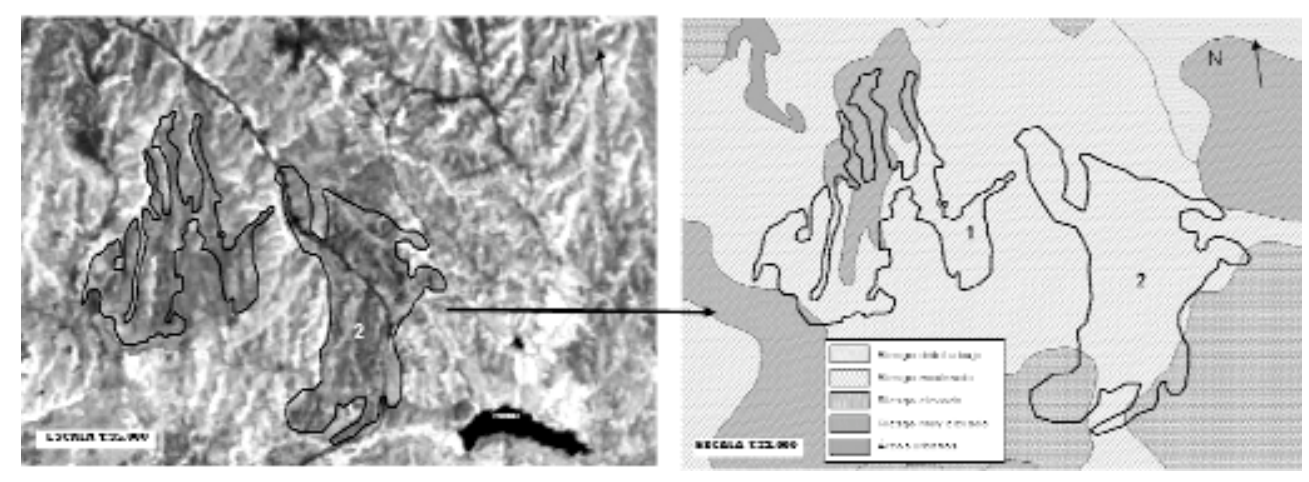

Figura 9. Identificación de los valores NDVI y categorías de riesgo en el interior de cada área quemada. Ejemplo: dos incendios ocurridos en el mes de diciembre de 1986. 


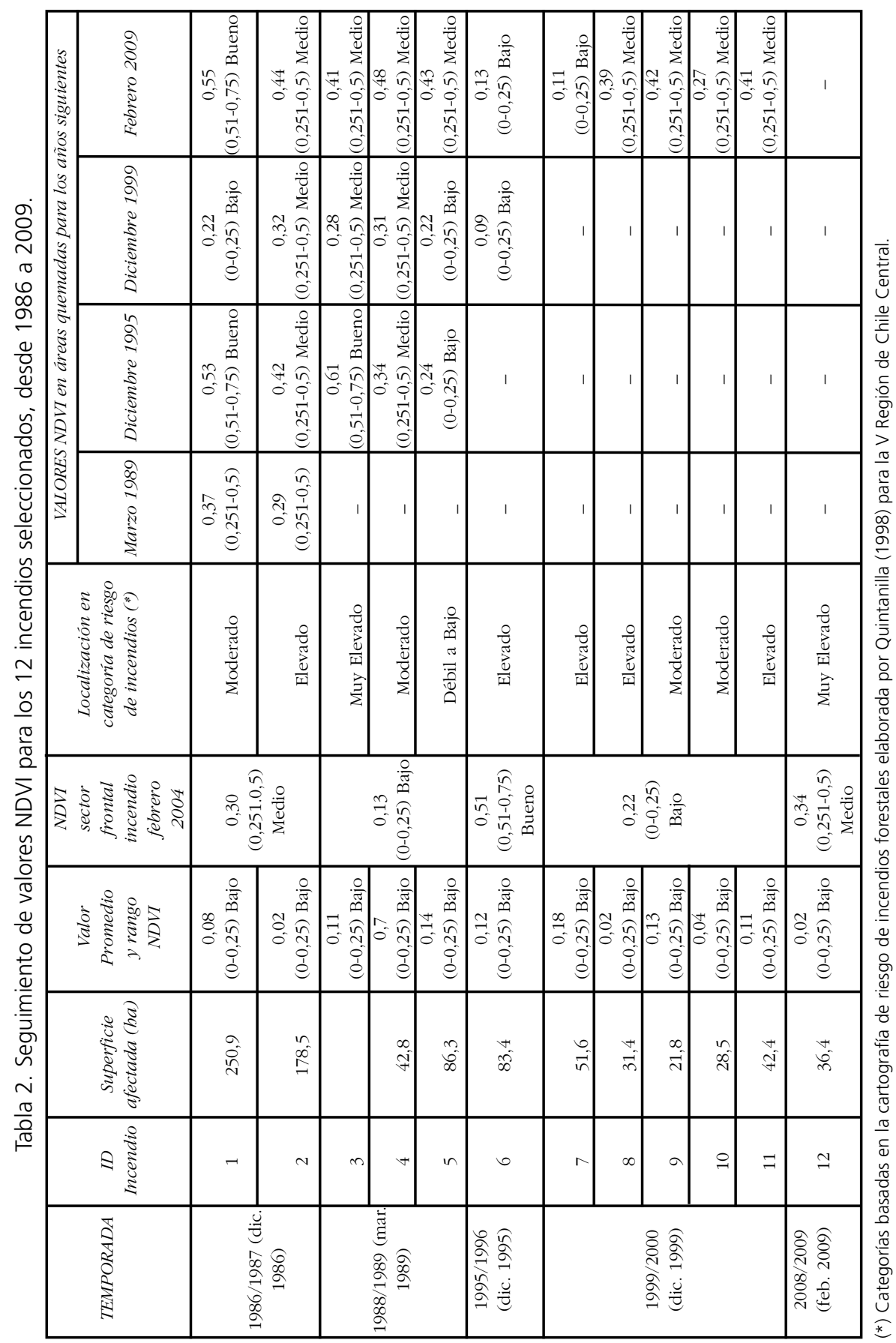


De acuerdo a los datos estadísticos, las localizaciones o lugares de inicio de ambos siniestros, se ubicaban en sectores de alta pendiente y muy próximo a la vía principal que conecta Santiago con Valparaíso, lo que demuestra la relación espacial que tiene el fenómeno de ocurrencia respecto a la concentración de actividades humanas.

Las variaciones del indicador NDVI para estos dos incendios permite inferir el daño en la cobertura vegetal fotosintéticamente activa a escasas semanas del fuego. Lo anterior se traduce en bajos valores del índice, sumado a las condiciones de baja humedad de los combustibles y alta inflamabilidad, aspectos propios de la vegetación mediterránea costera en meses cálidos de verano.

Los datos de la tabla anterior indican un bajo NDVI para el año 1995 en este sector, manteniendo su valor en 1999. La calificación de alto riesgo junto a la alta frecuencia de incendios, impide la recuperación de la vegetación, quedando detenida a estados de matorral degradado y leñosas altas abiertas.

La imagen satelital de diciembre de 1999 señala incendios superiores a 30 hectáreas localizados al norte del fundo Las Cenizas, a la salida Norte de Placilla y en sector de El Manzano a orilla del acceso sur a Valparaíso. Estos sectores han sido calificados en categorías de riesgo moderado y elevado, de acuerdo a la clasificación de Quintanilla (1998). Los valores NDVI muestran una actividad moderada a baja a diciembre de 1999, y mayores índices a febrero de 2009. La recurrencia de fuegos para los sectores quemados indican valores de 12 a 15 siniestros de tamaño inferiores a 10 hectáreas, generando fragmentos de vegetación joven entremezclados con leñosas altas y bajas del matorral degradado.

La imagen de febrero de 2009 señala un incendio de 36 hectáreas localizado al norte de Rodelillo, y muy cercano a sectores poblados. Se trata de lomajes suaves a moderados que han sido afectados por más de 12 incendios en los últimos 15 años, en áreas calificadas como de riesgo muy elevado. El valor NDVI identifica áreas recientemente quemadas caracterizadas por un valor cercano a cero, con fragmentos de vegetación invasora y escasa actividad fotosintética. En estos cerros es evidente la fragmentación del paisaje vegetal pues es posible apreciar una baja conectividad entre los parches de vegetación calificados como leñosas altas y bajas. La vegetación dominante corresponde a matorral nativo entremezclado con especies invasoras.

Con el apoyo de las bandas no correlacionadas (componentes principales), fue posible identificar con mayor claridad las áreas asociadas a los centros poblados (expansión). En tal sentido, el primer componente (97,5\%) de varianza explicada permite identificar una consolidación del espacio periurbano del sector sur de Valparaíso Metropolitano, junto a una rápida ocupación del suelo en las inmediaciones del Estero Marga-Marga. El colinaje costero representado en el fundo Hacienda Siete Hermanas y cerros aledaños, muestran un cambio importante en el uso del suelo, coincidiendo con las áreas de mayor riesgo de incendios (figura 10). 


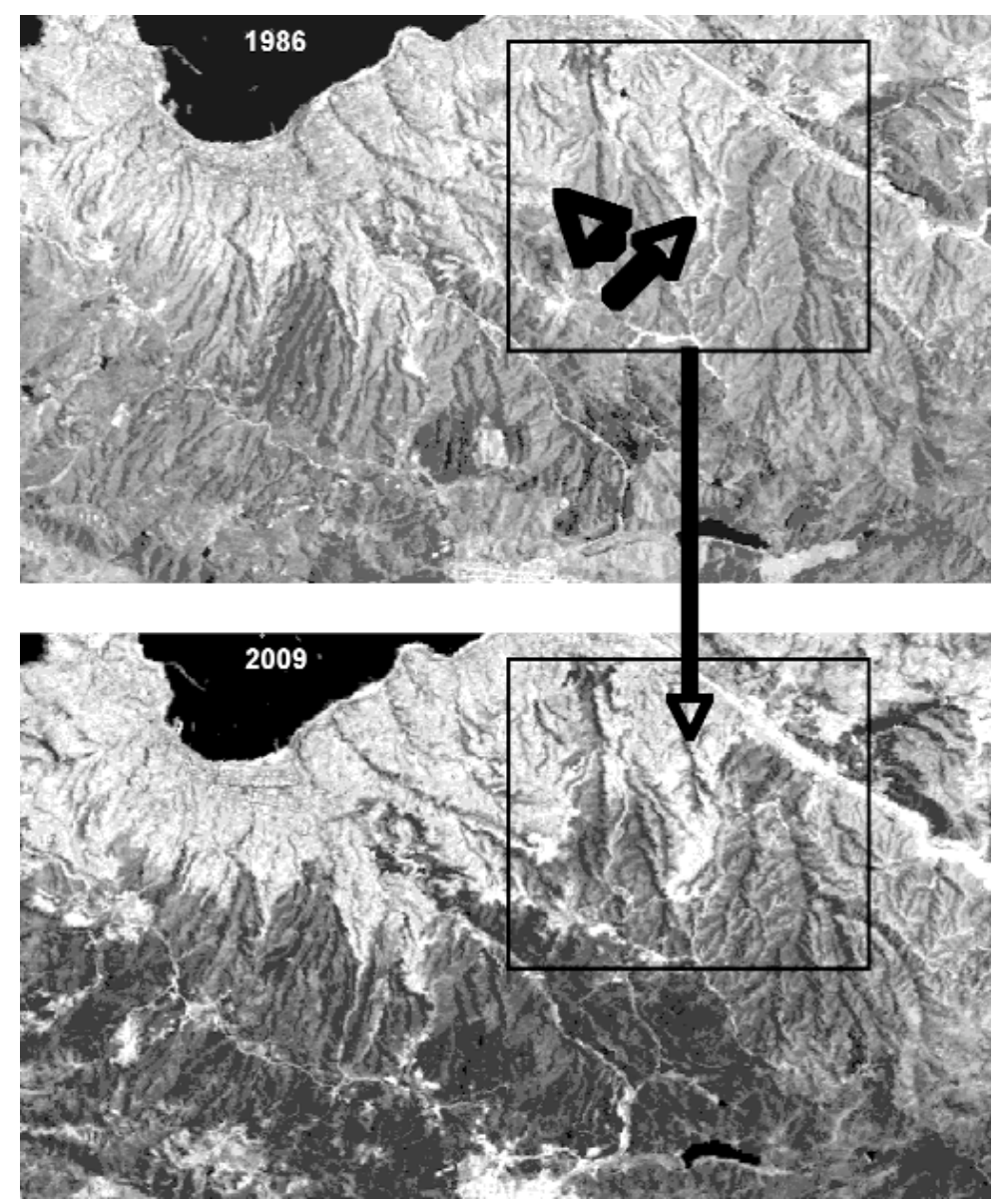

Figura 10. Cambios espaciales en la ocupación del suelo mediante la interpretación de componentes principales. El primer componente (grupos espectrales ortogonales) muestra la consolidación de los cascos urbanos de Valparaíso y Viña del Mar, junto al avance de la ocupación del suelo por viviendas aledañas a las quebradas del colinaje interior. Los cuadrantes señalan los cambios espaciales, en el sector local del incendio analizado (inmediaciones del Fundo Hacienda Siete Hermanas).

Este tratamiento de información utilizado para el reconocimiento de la vegetación y sus características espaciales (tamaño y forma de los parches), a base de la interpretación de celdas de 30 metros (imágenes satelitales), ha sido ampliamente utilizado en otras aplicaciones, también en el estudio de vegetación nativa de otras regiones mediterráneas del mundo. 
Tabla 3. Formaciones homogéneas (patrones espectrales), reconocidas en las imágenes. Superficies expresadas en hectáreas.

\begin{tabular}{|l|c|c|c|c|c|}
\hline \multirow{2}{*}{} & \multicolumn{5}{|c|}{$A \tilde{N O}$} \\
\cline { 2 - 6 } & 1986 & 1989 & 1999 & 2003 & 2009 \\
\hline Cuerpos de Agua & 803,78 & 803,78 & 803,78 & 803,78 & 797,02 \\
Vegetación-Leñosas Altas Abiertas & $1.394,11$ & $1.978,28$ & $2.636,08$ & $2.441,17$ & $2.476,54$ \\
Vegetación-Leñosas Altas y Bajas & $2.432,65$ & $3.153,97$ & $2.847,68$ & $3.164,53$ & $2.993,72$ \\
Vegetación-Leñosas Bajas & & & & & \\
Herbáceas Abiertas & $1.817,50$ & $1.743,06$ & $1.623,98$ & $1.637,00$ & $2.021,33$ \\
Vegetación-Herbáceas & $1.907,44$ & $1.433,39$ & $1.311,62$ & $1.225,41$ & $1.136,16$ \\
Vegetación-Leñosas Bajas & $1.847,19$ & $1.285,11$ & $1.147,37$ & $1.064,22$ & 936,74 \\
Poblado-Desnudo & $1.899,69$ & $1.499,95$ & $1.383,87$ & $1.273,30$ & $1.016,12$ \\
Poblado-Alta Densidad & $2.035,94$ & $1.984,73$ & $2.074,61$ & $1.977,93$ & $2.004,83$ \\
Poblado-Densidad Media & $1.664,31$ & $1.884,48$ & $2.036,68$ & $2.142,27$ & $2.271,01$ \\
Poblado-Densidad Media a Baja & 263,01 & 298,86 & 199,95 & 336,00 & 383,42 \\
\hline
\end{tabular}

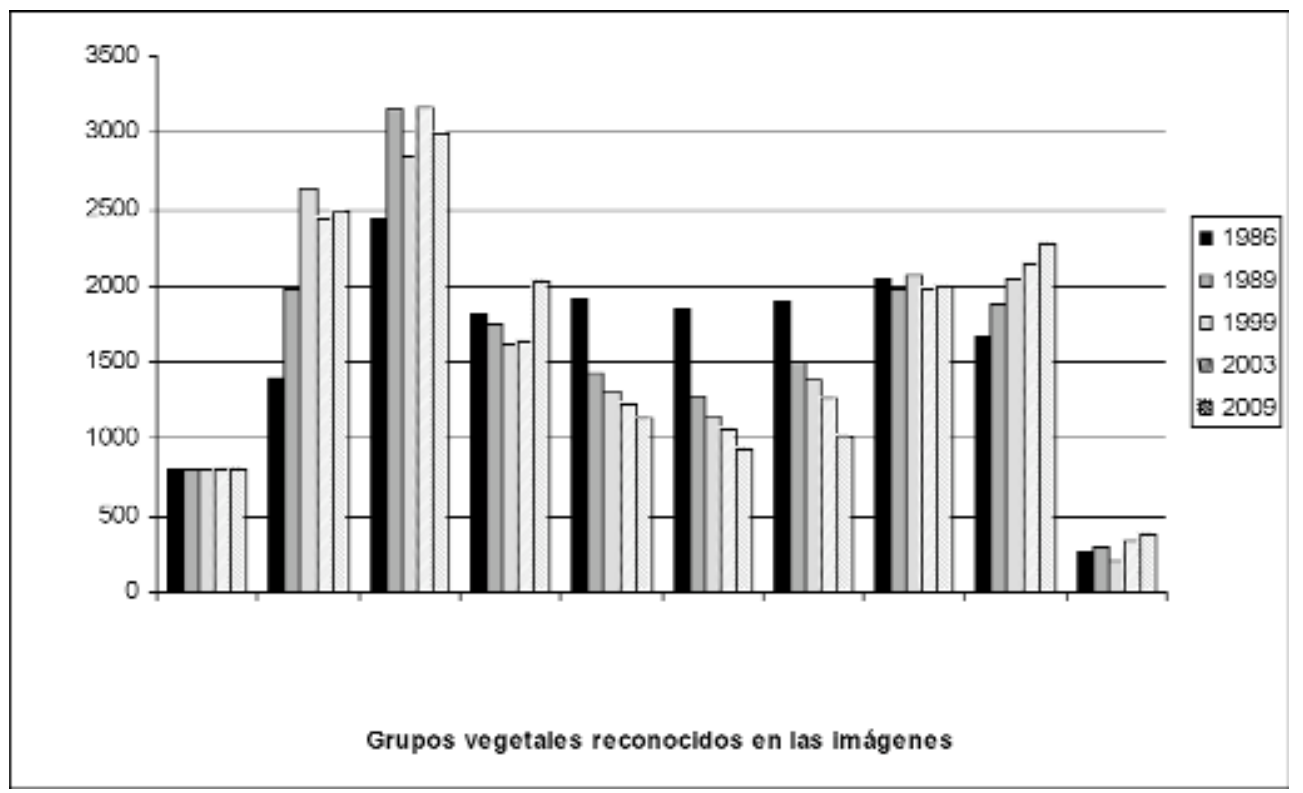

Gráfico 2. Cambios en las grandes formaciones vegetales reconocidas en la serie de imágenes satelitales, en un área de estudio aproximada de $16 \mathrm{~km}^{2}$. 
La cartografía de cambios en el paisaje vegetal a escala semidetallada (1:50.000), fue elaborada sobre la base de la interpretación de patrones espectrales para las imágenes satelitales Landsat de los años 1998, 2003 y 2009. Adicionalmente, en este proceso se utilizó como apoyo la información contenida en las fotografías aéreas del año 2001, con el propósito de verificar con mayor detalle las variaciones experimentadas por la vegetación al interior del área afectada.

Para efectuar las comparaciones en los cambios espaciales a escala local (1:15.000), se consideró la presencia o modificación de la vegetación, como también la cantidad de fragmentos presentes para categoría de formación vegetal. La tabla 4 y los gráficos 3 y 4 ilustran esta información.

Tabla 4. Comparación en la presencia (recuadros indicados con una " $X$ ") o ausencia de formaciones vegetacionales para los años 1998, 2003 y 2009.

\begin{tabular}{|c|c|c|c|c|c|c|c|c|c|}
\hline \multirow{3}{*}{$A \tilde{N} O$} & \multicolumn{9}{|c|}{$\begin{array}{l}\text { Nomenclatura de formaciones vegetales de acuerdo } \\
\text { a la cartografía de combustibles elaborada por Quintanilla (1998) }\end{array}$} \\
\hline & 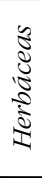 & 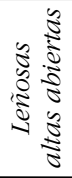 & 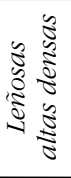 & 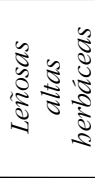 & 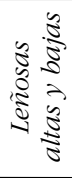 & 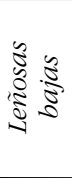 & 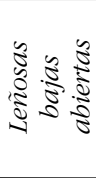 & 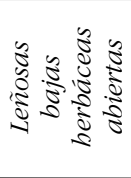 & 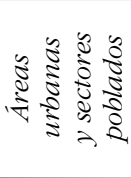 \\
\hline & 1 & 2 & 3 & 4 & 5 & 6 & 7 & 8 & 9 \\
\hline $\begin{array}{l}1998 \\
2003 \\
2009\end{array}$ & $\begin{array}{l}X \\
X\end{array}$ & $\begin{array}{l}\mathrm{X} \\
\mathrm{X} \\
\mathrm{X}\end{array}$ & $\begin{array}{l}\mathrm{x} \\
\mathrm{X}\end{array}$ & $\mathrm{x}$ & $\begin{array}{l}\mathrm{x} \\
\mathrm{X}\end{array}$ & $\mathrm{x}$ & $\begin{array}{l}\mathrm{x} \\
\mathrm{X} \\
\mathrm{X}\end{array}$ & $\begin{array}{l}\mathrm{x} \\
\mathrm{X}\end{array}$ & $\begin{array}{l}x \\
X \\
X\end{array}$ \\
\hline
\end{tabular}
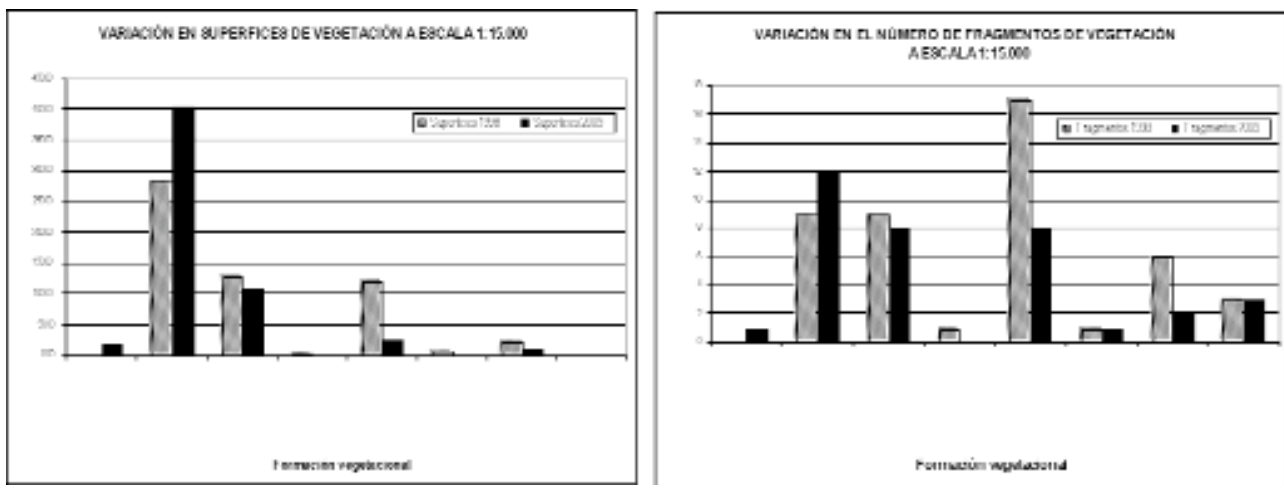

Gráficos 3 (izquierda) y 4 (derecha). Variaciones experimentadas por la vegetación, en cuanto al número de fragmentos presentes en el sector local (Escala 1:15.000), y la composición de ellos. 
Estos resultados ponen en evidencia las transformaciones presentes en los patrones de recubrimiento de la vegetación como en la composición de ellos. Las variaciones más evidentes se producen en las categorías "leñosas altas densas" y "leñosas altas y bajas". El paso reiterado del fuego entre los años 1998 a 2009 trae como consecuencia una disminución en superficie de estas formaciones, junto a un aumento en la fragmentación en sectores con presencia de leñosas altas abiertas.

\section{Conclusiones}

Sobre la base del análisis de los registros de incendios en el SIG, y los resultados derivados del análisis de componentes principales y NDVI, se verifica que el problema de los incendios forestales tiende a aumentar espacialmente hacia las áreas con mayor demanda de suelo, precisamente en sectores de interfaz, acrecentando los niveles de gravedad de los incendios forestales y comprometiendo seriamente la supervivencia del paisaje vegetal nativo.

El área del colinaje costero, y en particular del sector comprendido entre Valparaíso-Viña del Mar, norte de Placilla, Rodelillo y accesos carreteros a centros poblados, presenta una alta densidad de incendios, con patrones de ocurrencia claramente identificados en las imágenes satelitales y en las bases estadísticas de incendios. Existen sectores que han sido afectados más de 40 veces considerando una unidad de superficie 100 hectáreas, en los últimos 25 años.

Sobre este espacio geográfico fue posible identificar patrones de movilidad tanto en la ocurrencia de incendios como en la extensión de éstos. Conforme las imágenes satelitales señalan un leve aumento en el perímetro del contorno urbano de Valparaíso y Viña del Mar, la sobreposición de registros de incendios derivados de los antecedentes estadísticos de la Corporación Nacional Forestal, indica justamente un aumento en el número de siniestros asociado al crecimiento urbano periférico, además del aumento de éstos a orilla de caminos y sectores de quebradas.

Respecto al tamaño y forma de los incendios, se aprecian patrones de recurrencia de grandes eventos localizados al norte de la localidad de Placilla, Fundo Las Cenizas, sectores de El Salto y Jardín Botánico, Aeródromo Rodelillo, Ruta 68, Ruta Las Palmas y sectores altos de Viña del Mar. En todos ellos, se aprecian fuegos por sobre las 40 hectáreas que se suceden recurrentemente, y que afectan gravemente a la continuidad de la regeneración de los parches vegetales nativos.

El análisis estacional para la actividad fotosintética fue estudiado mediante el empleo del indicador NDVI. Los valores calculados para las imágenes satelitales, 
muestran una importante oscilación, conforme las áreas quemadas son pobladas por el manto vegetal. Aunque este valor varía ostensiblemente de acuerdo a la disponibilidad de agua por parte de las plantas y en forma indirecta por la estación del año en que se mide, existen evidencias que permiten señalar una mayor actividad fotosintética en áreas donde la vegetación ha estado sometida a constantes disturbios producto del fuego. Sin embargo, no es posible establecer conclusiones claras respecto a la relación de este índice con la recuperación de la vegetación en el área de estudio, principalmente por la insuficiencia de información entre períodos de imágenes, $\mathrm{y}$ en donde se ha concentrado una importante cantidad de incendios pequeños (menores a 5 hectáreas) que distorsionan los resultados de este indicador.

\section{Bibliografía}

Burgan, R. (1995). Use of Remotely Sended data for Fire Danger Estimation. Proc. Remote Sensing and GIS. Applications to Forest Fire Management. EARSEL. Universidad de Alcalá de Henares. España. 77-95.

Calle, A.; Casanova, J. (2002). Cartografía de áreas afectadas por incendios forestales. Dpto. de Física Aplicada. Facultad de Ciencias. Ponencia. Curso de Formación de Formadores sobre Aplicaciones de la Teledetección en la Lucha contra los Incendios Forestales. Agencia Española de Cooperación Internacional. Centro de Formación de la Cooperación Española. Cartagena de Indias, Colombia.

Castillo, M. (2006). El cambio del paisaje vegetal afectado por incendios en la Zona Mediterránea Costera de la Quinta Región de Chile. Tesis Magíster en Geografía. Universidad de Chile, 155p.

Chuvieco, E. (2000). Fundamentos de Teledetección Espacial. Ediciones Rialp S.A. Madrid. 568p. Tercera Edición Revisada.

Conaf (2005). Registros estadísticos sobre ocurrencia y causas de incendios forestales para la V Región de Chile, período 1986-
2005. Inédito. Bases de datos computacionales.

Dirección Meteorológica de Chile (2005). Antecedentes estadísticos de precipitaciones y temperaturas para las comunas de Valparaíso y Viña del Mar. Documento inédito.

Fuller, D. (2001). Forest fragmentation in Loudon Country, Virginia (USA), evaluated with multitemporal Landsat imagery. Research article. Landscape Ecology 16: 627-642. Kluwer Academic Publishers.

Gergel, S.; Turner, M. (2002). Learning Landscape Ecology: A practical Guide to Concepts and Techniques. Book Reviews. Landscape Ecology 17: 91-93. Kluwer Academic Publishers.

Quintanilla, V; Castro, R. (1998). Seguimiento de las Cubiertas Vegetales Post-Incendios Forestales en la Zona Mediterránea Costera de Chile. Serie Geográfica. Vol.7., p.147-154.

Quintanilla, V. (1998). Los incendios de vegetación en el Cordón Costero de Chile Central. El apoyo de la cartografía para su gestión en la prevención y análisis. Caso de estudio. En: Contribuciones científicas 
y tecnológicas. Universidad de Santiago de Chile. Area Ingeniería y Tecnología. Año XXVI. №120. 27p.

Quintanilla, V. (1999). Modificaciones por efecto del fuego en el bosque esclerófilo de quebradas húmedas de Chile Central y su incidencia en la Palma chilena. En: Revista Terra Australis. Instituto Geográfico Militar. №44, 7-18.

Quintanilla, V. (2000). Influencia del fuego en el desequilibrio ecológico de la vegetación en la zona mediterránea de Chile: casos de estudio. En: Investigaciones Geográficas. №34, 3-14. Universidad de Chile.

SEVEIF (2010). Aplicación y adaptación del modelo SEVEIF para la evaluación socioeconómica del impacto de incendios forestales en la Provincia de Valparaíso, Chile. Agencia Española de Cooperación Internacional para el Desarrollo (AECID). 51p.

Villaseñor, R. (1977). Unidades de vegetación de los cerros de la provincia de Valparaíso, Chile. 6p. Inédito. 